\title{
CONTROLLED VENTILATION IN THE TREATMENT OF STATUS ASTHMATICUS IN CHILDREN ${ }^{*}$
}

\author{
E. J. RHINE, M.B., CH.B., AND J. K. Rosales, M.D., F.R.C.P. (c)
}

ASTHMA Is DEFINED as intermittent spells of bronchospasm with symptom-free periods in a child who has a history or family history of an allergic condition. When the bronchospasm does not respond to bronchodilator treatment, or when extensive plugging of the bronchioles with sticky opalescent mucus occurs, the child is in status asthmaticus. ${ }^{1}$

Although the large majority of children admitted to hospital respond to conservative treatment, there is a definite incidence of children who do not respond to these measures, in whom the condition results in respiratory failure and death. ${ }^{2.3} \mathrm{~A}$ recent study from England of the mortality rate from asthma in all age groups has shown it to have almost doubled in the period from 1959 to 1966. In the same study, in the 10-to-14-year age group, the death rate had increased eight times, accounting for 5.7 per cent of all deaths in that age group and equalling the number of deaths caused by leukemia and pneumonia. Smaller increases in mortality from asthma have been reported from Australia, Japan, Western Europe, and the United States.

\section{Material}

During the period January 1964 to December 1967 a total of 589 patients with asthma were admitted to the Montreal Children's Hospital, of whom one died from status asthmaticus. Since December 1967, seven cases of status asthmaticus have failed to respond to medical therapy, resulting in respiratory failure, and have been treated by the use of controlled ventilation (Table I). The patients ranged in age from 4 to 16 years, and the period of mechanical ventilation varied from twelve hours to seven days. It is interesting to note that four of the seven

TABLE 1

Cases of Status Asthmaticus Treated with Controlled Ventilatron

\begin{tabular}{cccc}
\hline \hline Patient no. & $\begin{array}{c}\text { Age } \\
\text { (yrs) }\end{array}$ & Sex & $\begin{array}{c}\text { Time on } \\
\text { respirator }\end{array}$ \\
\hline 1 & 4 & M & 30 hrs \\
2 & $5 \frac{1}{2}$ & F & 7 days \\
3 & $2 \frac{1}{2}$ & F & 36 hrs \\
4 & 16 & M & 48 hrs \\
5 & $4 \frac{1}{2}$ & F & 12 hrs \\
6 & $4 \frac{1}{2}$ & F & 65 hrs \\
7 & 13 & F & $5 \frac{1}{2}$ days \\
\hline
\end{tabular}

'From the Department of Anaesthesia, Montreal Children's Hospital, and McGill University. 
cases occurred in the months of September and October, and three of the four in a two-week period in October, a time when the environmental temperature and humidity are dropping. A retrospective study $y^{5}$ of hospital admissions for the treatment of asthma in the Los Angeles area has shown a similar seasonal incidence.

\section{METHOD}

The criterion for the institution of controlled ventilation in these patients was a rapidly progressive respiratory failure in spite of adequate medical therapy, manifested clinically by (1) severe inspiratory retractions, (2) barely audible wheezing and breath sounds, (3) minimal thoracic movement with hyperinflation, (4) poor muscle tone, (5) a depressed level of consciousness and lack of response to painful stimuli, (6) the presence of cyanosis, in spite of high inspired oxygen concentrations. This clinical impression was substantiated by estimation of the blood gas status of the child, which invariably showed a rapidly rising $\mathrm{PcO}_{2}$ in relation to that obtained at the time of admission (Table II).

Before a final decision was made to use controlled ventilation a chest X-ray with AP and lateral projections was taken to rule out the presence of pneumothorax or mediastinal emphysema.

In these seven cases a nasotracheal tube has proved to be a satisfactory means of applying intermittent positive pressure ventilation and can be used as a route for suctioning. Prior to intubation the child is sedated with pentobarbital $3 \mathrm{mg} / \mathrm{kg}$ intravenously and preoxygenated. Intubation is performed following the administration of succinylcholine $1 \mathrm{mg} / \mathrm{kg}$ intravenously.

Paralysis is maintained by the use of laudexium methyl sulphate (Laudolissin), which has an action similar to d-tubocurare but of a longer duration, and is said to produce no ganglionic blockade or histamine release. ${ }^{6}$ Initially laudexium is given in a dosage of $0.5 \mathrm{mg} / \mathrm{kg}$ intravenously, and this dose is repeated until complete muscle paralysis has been obtained. Further doses of $0.5-1.0 \mathrm{mg} / \mathrm{kg}$ are given intravenously every two hours, and sedation is continued by the use of pentobarbital $3 \mathrm{mg} / \mathrm{kg}$ intramuscularly every four hours during the period of controlled ventilation.

The volume-cycled respirator is adjusted to obtain maximal ventilation within the limits of the asthmatic condition. The basic respiratory defect in children with

TABLE II

Mean Bloon Gas Values of Patients with Status Asthmaticus Treated by Controlled Ventilation

\begin{tabular}{|c|c|c|c|}
\hline & $\mathrm{pH}$ & $\underset{(\mathrm{mm} \mathrm{Hg})}{\mathrm{PcO}_{2}}$ & B.E. \\
\hline Admission & $\begin{array}{c}7.17 \\
(6.98-7.25)\end{array}$ & $\begin{array}{c}67 \\
\langle 51-78)\end{array}$ & $(-5--12)$ \\
\hline Before respirator & & $\begin{array}{c}100 \\
(72-143)\end{array}$ & $\left(-10^{-5}-1\right)$ \\
\hline & $\begin{array}{r}7.42 \\
(7.36-7.49)\end{array}$ & $\begin{array}{r}46 \\
(43-49)\end{array}$ & $\begin{array}{c}+4 \\
(+1-+11)\end{array}$ \\
\hline Off respirator & $\begin{array}{r}7.46 \\
(7.43-7.49)\end{array}$ & $\begin{array}{c}37 \\
(32-40)\end{array}$ & $(+2-+4)$ \\
\hline
\end{tabular}


status asthmaticus is a decrease in the calibre of the bronchioles due to smooth muscle spasm, oedema of the mucosa, and retained secretions. These lead to an increase in the airway resistance with air trapping distal to the obstruction. A high inspiratory pressure often has to be employed to achieve an adequate tidal volume, with a slow inspiratory flow rate to obtain optimal distribution. By ausculation of the duration of the expiratory wheeze the time necessary for this phase of respiration can be determined, and air trapping avoided.

Although the tidal volume achieved may be adequate, the minute ventilation may not be, due to the prolonged expiratory phase. The initial blood gas determinations may well show the $\mathrm{PCO}_{2}$ not to be reduced towards normal (Fig. 1).

The inspired gases are adequately humidified using a cascade humidifier, and inspired oxygen concentration is measured regularly. Normal saline is instilled prior to suction through the nasotracheal tube to remove the tenacious secretions present. Suctioning is performed at least once an hour, using a sterile technique. Frequent postural drainage and positioning of the patient is also carried out to help remove the secretions.

Continuous monitoring of these sick children is important. In addition to the

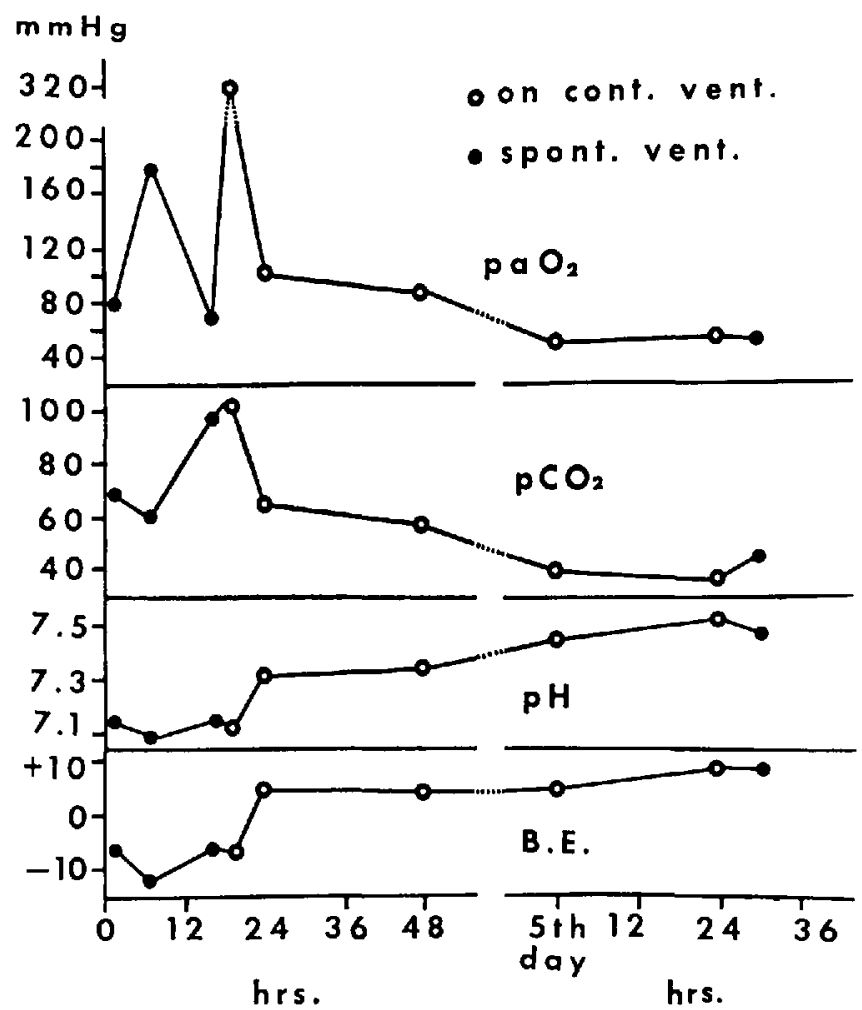

Figure 1. Blood gas values from case no. 7 , demonstrating initial rise in $\mathrm{Pa}_{\mathrm{CO}_{2}}$ after commencement of controlled ventilation, followed by a slow return to normal values over the subsequent five days. The low $\mathrm{Pa}_{\mathrm{O}_{2}}$ after five days of ventilation was due to an extensive pneumonia. 
routine vital signs taken at half-hour intervals or less if indicated, an ECG with visual and audible signals is used. If there is any evidence of right heart failure or mediastinal compression, then the central venous pressure is also monitored continuously.

The blood gas status of the child is measured at regular intervals, most frequently at the commencement of the period of controlled ventilation. This is best achieved by the use of an in-dwelling arterial cannula so that samples may be obtained with ease as required.

All the personnel engaged in the care of the patient, both medical and nursing, are made aware of the possibility of a tension pneumothorax or mediastinum developing during the time of controlled ventilation. A tray with all the equipment necessary for the rapid insertion of a chest tube is placed at hand ready for immediate use if required.

Controlled ventilation is continued until there is clinical evidence of diminution in the severity of the bronchospasm, which may be either spontaneous or following the administration of sympathomimetic drugs. Controlled ventilation is terminated when there has been improvement in the clinical status, return of the blood gases to normal levels, and the use of normal respiratory parameters for ventilation. The chest X-ray should also show a reduction in the hyperinflatory state and no areas of collapse.

Following the return of spontaneous respiration, assisted ventilation is used until adequate respiration is present. The child is then allowed to breathe spontaneously, the nasotracheal tube remaining in situ. Extubation is performed when the ventilatory status is satisfactory, as evidenced by the clinical state of the patient and the blood gases.

\section{Complications}

The complications which were present before, during, and following the use of controlled ventilation in our seven patients are shown in Table III. The pneumomediastinum present on admission in one patient delayed the final decision to use controlled ventilation, the $\mathrm{Po}_{2}$ being maintained by the administration of oxygen by face mask. A nasotracheal tube was used in this patient even though she had a pneumomediastinum, close observation being maintained after commencement of controlled ventilation for signs of mediastinal compres-

TABLE III

CoMplications

\begin{tabular}{llc}
\hline \hline & & Cases \\
\hline Before controlled ventilation & pneumomediastinum & 1 \\
& lobar collapse & 2 \\
During controlled ventilation & pneumomediastinum & 4 \\
& subcutaneous emphysema & 3 \\
& pneumothorax & 3 \\
& pneumoperitoneum & 1 \\
After controlled ventilation & pneumonia & 1 \\
& stress ulcer & 1 \\
\hline
\end{tabular}


sion. If these signs had occurred, a tracheostomy would have been performed to allow the entrapped air to escape through the fascial planes, and as a route by which controlled ventilation could have been continued. ${ }^{7}$ However, this complication did not occur, although subcutaneous emphysema developed in the neck, as it did in two other cases.

Pneumomediastinum occurred during ventilation in four other cases, and was associated with a pneumothorax in three of these. In one patient pneumoperitoneum was present in addition. A chest tube was promptly inserted whenever a pneumothorax was diagnosed. Pneumomediastinum and pneumoperitoneum alone were treated conservatively.

Lobar collapse was present in two patients prior to intubation and ventilation, but re-expansion occurred following suctioning and reduction in the severity of the brochospasm. However, another patient developed pneumonia with consolidation after being ventilated for four days. This responded slowly to medical treatment accompanied by vigorous physiotherapy and positioning. The same patient developed a stress ulcer with gastric bleeding less than 48 hours after controlled ventilation had been terminated. She underwent a laparotomy after which she was ventilated for a further 24 hours. The remainder of her hospital stay was uneventful.

\section{COMMENT}

The use of mechanical ventilation in the treatment of status asthmaticus has been well documented. ${ }^{8-10}$

It is mandatory that the patient in status asthmaticus receive complete and aggressive medical therapy prior to the use of mechanical ventilation. However, mechanical ventilation should not be delayed until one is presented with a hypoxic hypercarbic child on the verge of cardiac arrest. Conversely, mechanical ventilation for the treatment of status asthmaticus is associated with the frequent occurrence of dangerous complications which require prompt diagnosis and treatment. The most important criterion for the use of mechanical ventilation in these patients, in our opinion, is the presence of clinical cyanosis, or a $\mathrm{Pa}_{\mathrm{O}_{2}}$ below $60 \mathrm{~mm} \mathrm{Hg}$ in spite of a high inspired oxygen concentration.

In the initial phase of controlled ventilation much can be gained by the use of manual ventilation to assess the compliance of the chest, and manual ventilation should be continued until one is satisfied that complete muscle paralysis had been obtained. Controlled mechanical ventilation, when established, is maintained by the use of a volume-cycled respirator. The first three patients in this series were ventilated by means of a pressure-cycled respirator with which it was difficult to obtain satisfactory ventilation in the initial period. The inadequacy of ventilation in one case resulted in the patient's being manually ventilated for a period of eight hours until the bronchospasm became less severe and it was possible to continue adequate ventilation with a pressure-cycled ventilator.

To embark on this form of therapy in these extremely sick children demands that experienced medical personnel be immediately available on a 24 -hour basis, together with nurses trained in the care of children on a respirator, and adequate laboratory facilities. 


\section{SUMMARY}

Seven cases of respiratory failure due to status asthmaticus have been treated at the Montreal Children's Hospital by the use of controlled ventilation since December 1967. Comment has been made on the criteria for the commencement of treatment and on the subsequent management during the period of controlled ventilation. Emphasis has been placed on the potential complications which may arise, and on the necessity of an organized team's being constantly available.

\section{RÉSUMÉ}

Depuis décembre 1967, on a traité sept cas de défaillance respiratoire dûe à un status asthmaticus en utilisant la ventilation contrôlée. Les indices du début de la ventilation contrôlée ont été essentiellement ceux de Downes et autres; cependant on a attaché plus d'importance à la présence de cyanôse et d'un basse $\mathrm{Pa}_{0_{2}}$.

La ventilation contrôlée à l'aide d'un ventilateur à volume en circuit a été complétée par les myorésolutifs et la sédation a été maintenue au cours de la période de paralysie.

Ces sept cas ont présenté fréquemment des complications dont la plupart auraient pu être dangereuses si elles n'étaient pas diagnostiquées précocement et traitées convenablement. Il faut une unité de soins intensifs bien organisée, et des facilités de laboratoires adéquates si l'on veut tenter ce genre de thérapie pour ces enfants dangereusement malades.

\section{REFERENCES}

1. Bates, D. V. \& Chrustie, R. V. Respiratory Function in Disease. Philadelphia: Saunders (1964), p. 131.

2. Ruchards, W. \& Patrick, J. R. Death from Asthma in Children. Am. J. Dis. Children. 110: 4 (1964).

3. Lanoff, G. \& Crawfond, O. Fatalities from Bronchial Asthma in Children. Annals of Allergy. 22: 349 (1964).

4. Speizer, F. E.; Doll, R.; \& Heaf, P. Observations on Recent Increase in Mortality of Asthma. Brit. Med, J. 1: 335 (1968),

5. Richards, W.; Siegei, S. C.; Strauss, J.; \& Digey-Leigh, M. Status Asthmaticus in Children. J.A.M.A. 201: 75 (1964).

6. Badman, R. I.; Monton, H. J. V.; \& WyliE, W. D. A New Synthetic Curarising Agent: Clinical Trial of Compound 20 (Laudolussin). Lancet. 2: 517 (1952).

7. Thaler, M. M.; Krugger, E.; McKee, J. A.; \& Fearnon, B. Treatment of Mediastinal and Subcutaneous Emphysema Complicating Asthma in Children. J. Paediat. 65: 75 (1964).

8. Beam, L. R.; Marcy, J. H.; \& MansmanN, H. C., JR. Medically Irreversible Status Asthmaticus in Children. J.A.M.A. 194: 967 (1965).

9. Downes, J. J.; Wood, D. W.; STriker, T. W.; \& Lecks, H. I. Diagnosis and Treatment: Advances in the Management of Status Asthmaticus in Children. Paediatrics. 38: 286 (1966).

10. Wood, D. W.; Downes, J. J.; \& Lecks, H. I. The Management of Respiratory Failure in Childhood Status Asthmaticus: Experience with 30 Episodes and Evolution of a Technique. J. Allergy. 42: 261 ( 1968 ). 